\title{
Su içeriği ve ısıl kür süresinin atık bazalt tozu esaslı geopolimer harçların fiziksel ve mekanik özelliklerine etkisi
}

\section{The effects of water content and thermal curing time on physical and mechanical properties of waste basalt powder based geopolymer mortars}

\author{
Serhat Çelikten" ${ }^{1 *}$ (D), İsmail İsa Atabey ${ }^{1}$ (D) \\ ${ }^{1}$ Nevşehir Hacı Bektaş Veli Üniversitesi, İnşaat Mühendisliği Bölümü, 50300, Nevşehir, Türkiye
}

\section{Özet}

Bu çalışmada bazalt taşı kesim atıkları ile üretilen geopolimer harçların mekanik ve fiziksel özellikleri araştırılmıștır. Bu amaçla 4 farklı su içeriği ile geopolimer harçlar üretilmiştir. Harçlarda aktivatör olarak sodyum silikat kullanılmıştır. Üretilen geopolimer harçlar 4, 8 ve 24 saat olmak üzere 3 farklı sürede $90^{\circ} \mathrm{C}$ 'de ssl küre tabi tutulmuştur. Harçlar üzerinde yayılma, su emme-boşluk oranı, eğilme dayanımı ve basınç dayanımı deneyleri gerçekleștirilmiştir. En yüksek dayanım değerlerine en düşük su içeriği ile üretilen harçlarda ulaşılmıştır. 4 saat, 8 saat ve 24 saat ısıl küre tabi tutulan harçlarda en yüksek 28 günlük basınç dayanımlarl sırasıyla 8,1 MPa, 17,7 MPa ve 28,6 MPa olarak elde edilmiştir. Bu deneyse çalışmanın bir sonucu olarak, atık bazalt tozunun geopolimer üretiminde değerlendirilebileceği ve bu sayede çevresel ve ekonomik fayda sağlanabileceği söylenebilir.

Anahtar kelimeler: Atık bazalt tozu, Geopolimer, Dayanım, Isıl kür

\section{Giriş}

Madencilik ve endüstriyel faaliyetlerde atıkların azaltılması, son yıllarda temel çevre sorunlarından biri olmuştur. $\mathrm{Bu}$ nedenle, atıkları katma değerli ürünlere dönüştürmek için yeni teknolojiler geliştirmek oldukça önemlidir [1]. Puzolanlar doğal ve yapay olarak sınıflandırılırken doğal kaynaklar arasında volkanik kayaçlar en eski ve bol rezerve sahip olarak bilinir. Yapılarında yüksek miktarda silis ve zeolit içerirler. Son zamanlarda daha ekonomik ve çevresel etkileri azaltıcı puzolanik özelliklere sahip atıkların kullanılarak çimentoya alternatif bağlayıcı üretimi yaygınlaşmaktadır [2].

"Geopolimer" terimi, 1979'da Joseph Davidovits tarafindan sodyum ve potasyum gibi alkalilerle aktive edilmiş alüminosilikatları tanımlamak için kullanıldı [3]. Alkali ile harç üretiminde uçucu kül [4], yüksek firın cürufu [5], silis dumanı [6] gibi endüstriyel atıkların yanı sıra andezit tozu [7], mermer tozu [8] gibi doğal taşların işlenmesiyle ortaya çıkan atıklar da son zamanlarda kullanılmaktadır. Ayrıca atık tozları aktifleştirmek için sodyum hidroksit [9], sodyum silikat [10], sodyum hidroksitsodyum silikat karışımı [11, 12] sıklıkla kullanılan aktivatör çeşitleridir.

Alkali aktivatörlerle ilgili çalışmalar uzun süredir araştırmacılar tarafından büyük ilgi görmektedir. Bu bağlamda, atık toz malzemelerin alkali aktivatörler kullanılarak üretilmesi ile ilgili araştırmalar endüstriyel

\begin{abstract}
In this study, the mechanical and physical properties of geopolymer mortars produced with cutting waste of basalt stone has been investigated. For this purpose, geopolymer mortars made with four different water content. Sodium silicate was used as activator in the mortars. The produced mortars subjected to heat-curing for 4,8 and 24 hours at $90^{\circ} \mathrm{C}$, separately. The flowing, water absorption-porosity, flexural and compressive strength tests were performed on the mortars. The highest strength values were obtained on the mortars made with the lowest water content. The highest 28-day compressive strengths were obtained as 8.1 $\mathrm{MPa}, 17.7 \mathrm{MPa}$ and 28.6 MPa in mortars heat cured for 4 hours, 8 hours and 24 hours, respectively. Besides, it can be concluded that the waste basalt powder can be utilized for the geopolymer production and thus environmental and economic benefits can be obtained.
\end{abstract}

Keywords: Waste basalt powder, Geopolymer, Strength, Heat curing

atıkların çevresel etkileri nedeniyle kullanımına odaklanmıştır. Alüminosilikatların yeryüzünde en bol bulunan bileşikler olması nedeniyle, geopolimer üretme potansiyeline sahip, alümina ve silis açısından zengin çok sayıda hammadde kaynağı mevcuttur [13-17].

Doğal taş kesimi üretim süreci sonunda önemli oranda atık toz meydana gelmektedir. Tane boyutu $125 \mu$ dan daha küçük olabilen bu atık toz; hava, toprak ve su kirliliğine sebep olmaktadır. Ortaya çıkan tozun farklı alanlarda hammadde olarak kullanılması noktasında bazı araştırmalar yapılmaktadır [18]. Volkanik bir kayaç olan bazalt; lif katkı [19], agrega [20], mineral katkı [21] olarak kullanılabilirliği genel olarak araştırma alanlarını oluşturmaktadır. Ancak bu kayacın kesim atığı tozlarının agrega ve mineral katkı olarak kısmen kullanımının yanı sıra tamamen atık toz bağlayıcı olarak kullanılan alkali aktivasyon yöntemi de uygun bir araştırma alanıdır.

Önceki çalışmalarda atık bazalt tozunun çimento esaslı beton/harç üretiminde kullanımı üzerine birçok araştırma yapılmıştır. Ancak alkali aktivasyon yöntemleri kullanılarak bazalt tozunun farklı alanda değerlendirilmesinin etkinliği üzerine çalışmalar kısıtlıdır. Bu çalışmada, atık bazalt tozu sabit aktivatör içeriği ile sabit 1sıl kür sicaklığında aktive edilerek geopolimer harçlar üretilmiştir. Harçlar 4 farklı su içeriği ile üretilmiş ve 3 farklı sürede 1sıl küre tabi tutulmuştur. Üretilen harçların yayılma, su emme, boşluk oranı, eğilme dayanımı ve basınç dayanımı özellikleri araştırılmıştır.

\footnotetext{
* Sorumlu yazar / Corresponding author, e-posta / e-mail: scelikten@ nevsehir.edu.tr (S. Celikten)

Geliş / Recieved: 07.12.2020 Kabul/ Accepted: 18.12.2020 Yayımlanma/ Published: 15.01.2021

doi 10.28948/ngmuh. 836998
} 


\section{Materyal ve metot}

Çalışmada katı alümina silikat kaynağı olarak kullanılan atık bazalt tozu (ABT) Kayseri yöresinde bazalt kesimi yapan yerel bir firmadan temin edilmiştir. Tamamı $125 \mu \mathrm{m}$ elekten geçebilen atık malzeme karışımların su içeriğinde farklılık oluşmaması için etüvde $105{ }^{\circ} \mathrm{C}^{\prime}$ de 24 saat kurutulduktan sonra kullanılmıştır. ABT malzemesinin kimyasal kompozisyonu Tablo 1'de sunulmuştur. Geopolimer harç karışımlarında $0-4 \mathrm{~mm}$ tane boyutu aralığında dere kumu ve şehir şebeke suyu kullanılmıştır. Dere kumunun doygun kuru yüzey özgül ağırlığı 2.67 ve su emme oranı \%1.94'dür. Kuma ait elek analizi sonuçları Tablo 2'de verilmiștir. Karıșımlarda kullanılan ABT malzemesinin görünümü Şekil 1'de yer almaktadır. Aktivatör olarak da $\mathrm{ABT}$ ağırlığının \%10'u kadar $\mathrm{Na}_{2} \mathrm{O}$ içeren sıvı sodyum silikat kullanılmıştır. Yapılan bir ön çalışmada [22], $\mathrm{KOH}, \mathrm{NaOH}$ ve sıvı sodyum silikat içeriği ile üretilen bazalt esaslı geopolimer harçlarda en yüksek dayanım değerlerine sodyum silikat ile üretilen harçlarda elde edildiği rapor edilmiştir. Bu nedenle, bu çalışmada da sodyum silikat tercih edilmiş, farklı deney parametreleri ile daha yüksek mekanik özellikler elde edilmeye çalışılmıştır.

Tablo 1. Atık bazalt tozunun kimyasal kompozisyonu

\begin{tabular}{llll}
\hline Oksit & $\%$ & Oksit & $\%$ \\
\hline $\mathrm{SiO}_{2}$ & 46.73 & $\mathrm{Na}_{2} \mathrm{O}$ & 3.21 \\
$\mathrm{Al}_{2} \mathrm{O}_{3}$ & 16.42 & $\mathrm{TiO}_{2}$ & 2.72 \\
$\mathrm{CaO}$ & 10.97 & $\mathrm{~K}_{2} \mathrm{O}$ & 0.69 \\
$\mathrm{Fe}_{2} \mathrm{O}_{3}$ & 8.39 & $\mathrm{MnO}$ & 0.86 \\
$\mathrm{MgO}$ & 7.23 & $\mathrm{P}_{2} \mathrm{O}_{5}$ & 0.47 \\
\hline
\end{tabular}

Tablo 2. Dere kumu elek analizi değerleri

\begin{tabular}{lc}
\hline Elek Çap $1, \mathrm{~mm}$ & Geçen, \% \\
\hline 4.00 & 99.1 \\
2.00 & 65.1 \\
1.00 & 40.2 \\
0.5 & 21.3 \\
0.25 & 9.9 \\
0.125 & 3.7 \\
0.063 & 0.9 \\
\hline
\end{tabular}

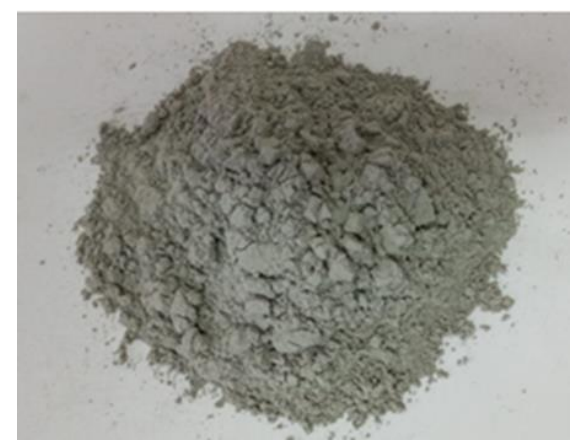

Şekil 1. Atık bazalt tozu (ABT)

Deneysel çalışmada ABT ile 12 farklı geopolimer harç karışımı oluşturulmuştur. Harç üretiminde 3 gözlü $4 \times 4 \times 16$ $\mathrm{cm}$ prizma kalıp için kullanılan malzeme miktarları Tablo 3 'de sunulmuştur. Karışımlar $0.31,0.35,0.40$ ve 0.45 olmak üzere 4 farklı su/ABT oranı ile oluşturulmuştur. En düşük su/ABT oranının 0,31 seçilmesinin sebebi $\% 10 \quad \mathrm{Na}_{2} \mathrm{O}$ oranında $228 \mathrm{gr} \mathrm{Na}_{2} \mathrm{SiO}_{3}$ içerisindeki su miktarının bağlayıcıya oranı 0.31 'e denk gelmesindendir. Karışımlarda öncelikle ABT ve aktivatör solüsyonları Hobart mikseri kabına yerleştirilmiş, kum daha sonra TS EN 196-1 standardında olduğu 30 sn içinde ilave edilmiştir. Üretilen karışımlar 3 gözlü prizma kalıplara döküldükten sonra 1 gün laboratuvar koşullarında ön küre tabi tutulmuş, daha sonra $90^{\circ} \mathrm{C}$ 'de 4,8 ve 24 saat olmak üzere 3 farklı sürede 1 sıl kür uygulanmıştır. Taze harçlara TS EN 1015-3 [23] standardına uygun olarak yayılma tablası deneyi gerçekleştirilerek işlenebilirlik değerleri belirlenmiştir. Harçlar üzerinde 1sıl kürden 7 ve 28 gün sonra TS EN 196-1 [24] standardına göre eğilme ve basınç dayanımı deneyleri gerçekleştirilmiştir.

Tablo 3. Harç karışımları

\begin{tabular}{cccccc}
\hline Seri & Karışım & ABT & Kum, g & $\mathrm{Na}_{2} \mathrm{SiO}_{3}, \mathrm{~g}$ & $\mathrm{Su}, \mathrm{g}$ \\
\hline \multirow{3}{*}{0.31} & $0.31-4$ & 450 & 1350 & 228 & 0 \\
& $0.31-8$ & 450 & 1350 & 228 & 0 \\
& $0.31-24$ & 450 & 1350 & 228 & 0 \\
\hline \multirow{3}{*}{0.35} & $0.35-4$ & 450 & 1350 & 228 & 19 \\
& $0.35-8$ & 450 & 1350 & 228 & 19 \\
& $0.35-24$ & 450 & 1350 & 228 & 19 \\
\hline \multirow{3}{*}{0.40} & $0.40-4$ & 450 & 1350 & 228 & 41 \\
& $0.40-8$ & 450 & 1350 & 228 & 41 \\
& $0.40-24$ & 450 & 1350 & 228 & 41 \\
\hline \multirow{3}{*}{0.45} & $0.45-4$ & 450 & 1350 & 228 & 63 \\
& $0.45-8$ & 450 & 1350 & 228 & 63 \\
& $0.45-24$ & 450 & 1350 & 228 & 63 \\
\hline
\end{tabular}

\section{Bulgular ve tartışma}

Çalışmada üretilen taze harçların yayılma değerleri Tablo 4 'te sunulmuştur. Su/ABT oranı 0.31 'den 0.45 'e çıkmasıyla yayılma değeri 128 mm'den 154 mm'ye ulaşarak 26 mm'lik bir artış meydana gelmiştir.

Tablo 4. Taze harçların yayılma değerleri

\begin{tabular}{lc}
\hline Karışım Grubu & yayılma, $\mathrm{mm}$ \\
\hline 0.31 & 128 \\
0.35 & 135 \\
0.40 & 143 \\
0.45 & 154 \\
\hline
\end{tabular}

$\mathrm{ABT}$ ile elde edilen sertleşmiş geopolimer numunelerinin su emme ve boşluk oranı değerleri Şekil 2'de verilmiş̧tir. Harçların boşluk oranları \%12.2 ile \%21.7 arasında değerler almıştır. En düşük boşluk oranı 0.31-24 kodlu harçlarda ulaşılırken, en yüksek boşluk oranı 0.45-4 kodlu harçlarda gözlenmiştir. Su içeriğinin azalması ile harçların boşluk oranları kademeli olarak azalmıştır. Öyle ki, 0.40 su/ABT içeriği ile üretilen harçların boşluk oranları 0.45 ile üretilenlere göre $\% 2$ ile $\% 4$ arasında daha düşük ve 0.31 su/ABT oranı ile üretilen harçların boşluk oranları da $\% 2.5$ ile $\% 4$ arasında daha düşük elde edilmiştir. Diğer taraftan, su içeriği fark etmeksizin harçlara uygulanan isıl kür süresi arttıkça genel itibariyle boşluk oranlarında da azalma meydana gelmiş̧ir. Isıl kür süresinin 4 saatten 24 saate çıkması ile harçların boşluk oranları \%1.3 ile \%3.5 arasında değişen oranlarda azalmıştır. ABT esaslı geopolimer harçların su emme değerleri \%5.8 ile $\% 10.8$ arasında elde edilmiştir. Harçların su emme değerleri su içeriğinin azalması ve 1sıl kür süresinin artması ile birlikte genellikle düşmüştür. $\mathrm{Bu}$ çalışmada üretilen $\mathrm{ABT}$ esaslı geopolimer 
harçların deney sonuçlarını kıyaslayabilecek çalışma çok kısıtlıdır. Bu nedenle, farklı öncü aluminosilikat malzemelerin kullanıldığı çalışmalarla bulgular kıyaslanmış ve tartışılmıştır. Yapılan bir çalışmada [25], dere kumu ile üretilen F sınıfı uçucu küllü geopolimer harçların su emme ve görünür boşluk özellikleri araştırılmıştır. 28 günlük basınç dayanımı $22 \mathrm{MPa}$ olan harçların su emme ve boşluk oranları sırasıyla \%11.79 ve \%21.51 olarak hesaplanmıştır. Çalışmamızda ise benzer dayanıma sahip ABT esaslı geopolimer harçların (0.35-24) su emme ve boşluk oranları sırasıyla \%6.9 ve \%14.5 olarak hesaplanmıştır. Diğer bir çalışmada [26], dere kumu ile volkanik kül esaslı geopolimer harçlar üretilmiştir. Üretilen harçlar $80^{\circ} \mathrm{C}^{\prime} \mathrm{de} 24$ saat 1sıl küre tabi tutulmuş̧ur. Çalışmada 28 günlük basınç dayanımı $30 \mathrm{MPa}$ olan geopolimer harçların su emme ve boşluk oranları sırasıyla yaklaşık olarak $\% 6$ ve $\% 13$ olarak hesaplanmıştır. Çalışmamızda ise benzer dayanıma sahip ABT esaslı geopolimer harçların (0.31-24) su emme ve boşluk oranları sırasıyla $\% 5.8$ ve $\% 12.2$ olarak hesaplanmıştır. $\mathrm{Bu}$ çalışmada üretilen $\mathrm{ABT}$ esaslı geopolimer harçların benzer dayanıma sahip uçucu küllü [25] ve volkanik küllü [26] geopolimer harçlara kıyasla daha düşük su emme ve boşluk oranlarına sahip olduğu görülmüştür.

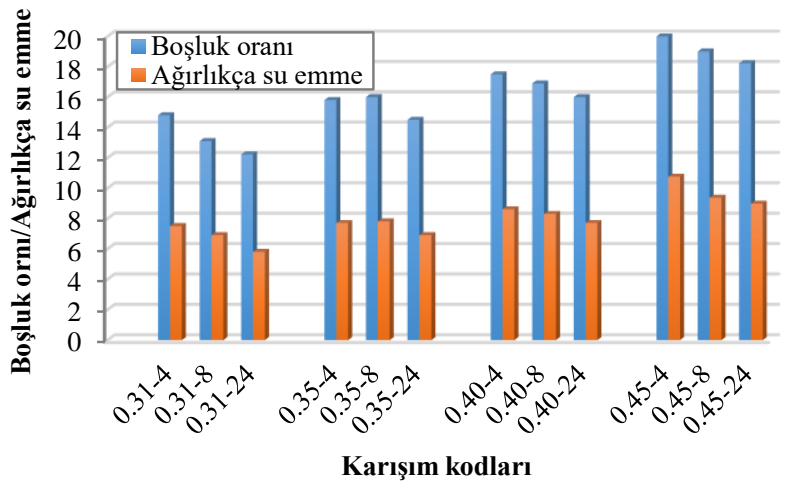

Şekil 2. Geopolimer numunelerin su emme-boşluk oranları

Sertleşmiş geopolimer numunelerin 7 ve 28 günlük eğilme dayanımları Şekil 3'de sunulmuştur. Harçların 7 günlük eğilme dayanımları 0.67 ile $5.2 \mathrm{MPa}$ arasında değişirken, 28 günlük eğilme dayanımları 0.88 ile $9.32 \mathrm{MPa}$ arasındadır. Harçların eğilme dayanımları su/ABT oranı azaldıkça artmıştır. Öyle ki, 0,31 su/ABT ile üretilen harçların eğilme dayanımı değerleri 0.45 ile üretilenlere göre yaklaşık \%80 oranında daha yüksek elde edilmişstir. Geopolimer bağlayıcılarda su sadece alümino silikatlı aktive edilecek malzemelerin çözünmesi için ortam sağlamakla kalmaz, aynı zamanda çeşitli iyon transferleri ile $\mathrm{Al}$ ve $\mathrm{Si}$ monomerik ve oligomerik türlerin polikondensasyonuna yardımcı olur [27, 28]. Ancak, bu rolünün dışında işlenebilirliği artırmak amacıyla kullanılan fazla miktardaki serbest su, bağlayıcı fazının daha boşluklu olmasına ve geopolimerlerin mekanik özelliklerinin olumsuz etkilenmesine yol açabilmektedir. $\mathrm{Bu}$ durum literatürde metakaolin [29], uçucu kül [30, 31] tabanlı geopolimer bağlayıcılar için de rapor edilmiştir.
Bununla birlikte, harçların eğilme dayanımları 1sıl kür süresinin artması ile birlikte belirgin bir şekilde artmıştır. Numunelerde en yüksek eğilme dayanımı değerleri 0.31-24 kodlu harçlarda elde edilirken, en düşük değerler $0.45-4$ kodlu harçlarda görülmüsşür.

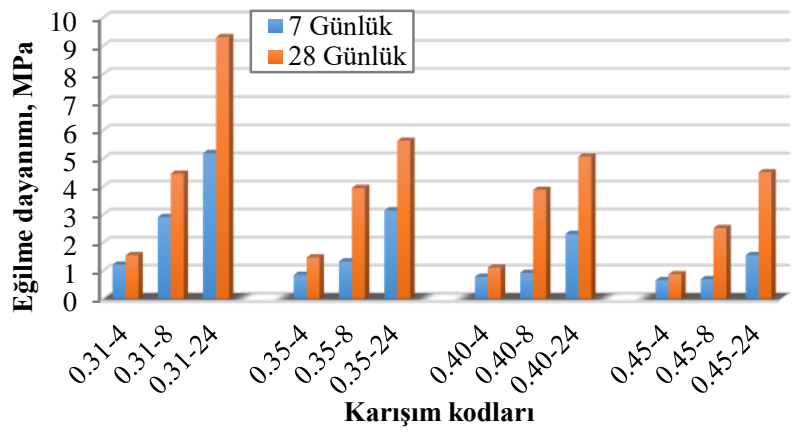

Şekil 3. Geopolimer harçların eğilme dayanımları

ABT esaslı geopolimer harçların basınç dayanımları 4 saatlik ısıl kür için Şekil 4, 8 saatlik ssıl kür için Şekil 5 ve 24 saatlik 1sıl kür için de Şekil 6'da verilmiştir. ABT ile üretilen geopolimer harçlarda en yüksek 28 günlük basınç dayanımı 28.6 MPa 0.31-24 kodlu harçlarda elde edilmiştir (Şekil 6). En düşük 28 günlük basınç dayanımı olan $6.4 \mathrm{MPa}$ ise 0.45-4 harçlarda gözlenmiştir (Şekil 4). Harçların basınç dayanımlardaki değişimler, eğilme dayanımlarında görülen değişimlere benzer olmuştur. Harçların basınç dayanımları su içeriğinin azalması ve 1 sıl kür süresinin artması ile birlikte belirgin bir şekilde artmıştır. Isıl kür süresinin artması ile harçlarda görülen dayanım artışı, ABT malzemesindeki amorf fazlardan $\mathrm{Al}$ ve Si iyonlarının isıl kür etkisiyle daha fazla çözünmesine bağlanabilir. Bu durum daha önce yapılan çalışmalarda metakaolin [32], uçucu kül [33] ve perlit [34] esaslı geopolimerler için de rapor edilmiştir. ABT tabanlı geopolimer harçlardan elde edilen bulgular da bu çalışmaların sonuçları ile uyumludur. Elde edilen sonuçlar düşük $\mathrm{Ca}$ içerikli geopolimer bağlayıcıların ısıl kür etkisinde benzer davranış sergilediğini göstermektedir. Bununla birlikte, harçların basınç dayanımları 7 günden 28 güne $\% 40$ ile $\% 300$ oranları arasında değişen oranlarda artmıştır. Kür yaşı ile harçların basınç dayanımlarında görülen artış daha kısa süre 1sıl küre maruz kalan harçlarda (4 ve 8 saat) 24 saat 1sıl küre tabi tutulan harçlara göre daha fazla olmuştur. Bunun nedeni olarak, uzun süre 1sıl küre tabi tutulan harçların nihai dayanıma daha yakın olması gösterilebilir.

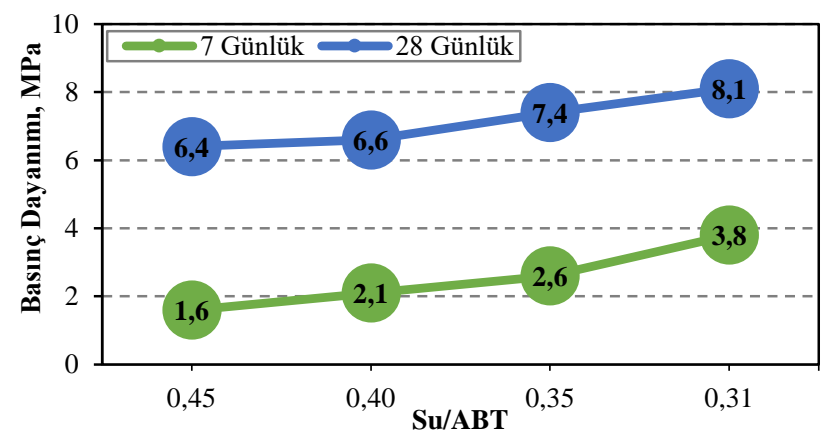

Şekil 4. 4 saat ısıl kür sonrası basınç dayanımları 


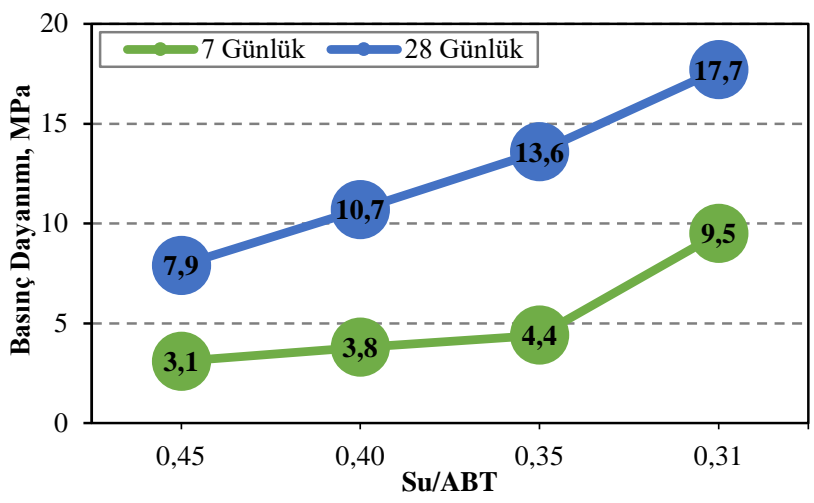

Şekil 5. 8 saat ısıl kür sonrası basınç dayanımları

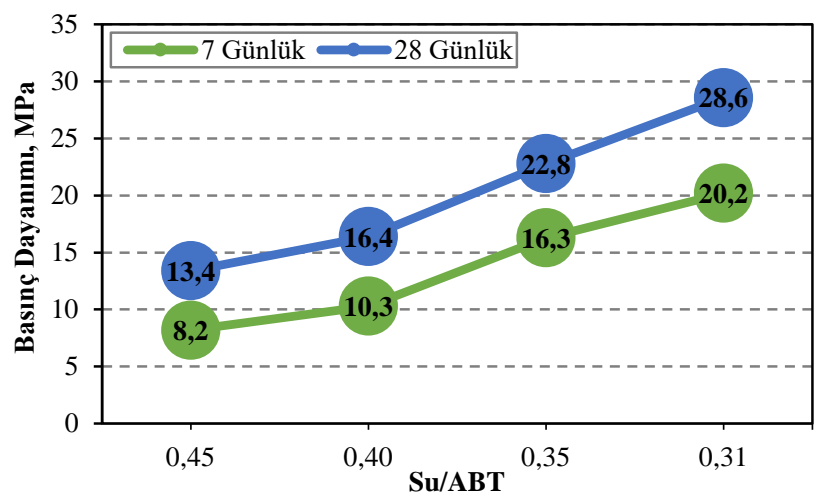

Şekil 6. 24 saat ısıl kür sonrası basınç dayanımları

\section{Sonuçlar}

$\mathrm{Bu}$ çalışmada, bazalt taşı kesim atölyelerinden çamur şeklinde ortaya çıkan kesim atıkları ile üretilen geopolimer harçların fiziksel ve mekanik özellikleri incelenmiştir.

- Harçların mekanik ve fiziksel özellikleri, harçlardaki su içeriğinin azalması ve 1sıl kür süresinin uzaması ile birlikte gelişmiştir.

- $\quad$ En düşük su emme ve en düşük boşluk oranı sırasıyla $\% 5.8$ ve $\% 12.2$ olarak elde edilmiştir.

- Bazalt kesim atıkları ile 24 saat ısıl kür süresi ve 0.31 su/ABT oranında 28 günlük eğilme dayanımı $9.32 \mathrm{MPa}$ ve 28 günlük basınç dayanımı $28.6 \mathrm{MPa}$ olan geopolimer harçlar üretilebilmiştir.

- Bazalt esaslı geopolimer harçlarda 8 saat gibi kısa sayılabilecek 1sıl kür süresinde düşük su içeriği ile 17.7 $\mathrm{MPa} 28$ günlük basınç dayanımı elde edilmiştir.

- Geopolimer harçların dayanım değerlerinde kür yaşı ile birlikte farklı oranlarda artışlar görülmüştür.

Yapılan deneysel çalışma neticesinde, bazalt taşı kesim atıklarının geopolimer üretimi açısından önemli bir potansiyele sahip olduğu anlaşılmıştır. Bu perspektif ile bu atıkların ekonomiye geri kazanımı ve çevreye verdiği zararların azaltılması mümkün olabilecektir. Ayrıca, bazalt taşı kesim atıklarının dayanıklılık özelliklerinin araştııılması sonraki çalışmalar için önerilir.

\section{Çıkar çatışması}

Yazarlar çıkar çatışması olmadığını beyan etmektedir.
Benzerlik oranı (iThenticate): $\% 6$

\section{Kaynaklar}

[1] G. Kürklü and G. Görhan, (2019). Investigation of usability of quarry dust waste in fly ash-based geopolymer adhesive mortar production. Construction and Building Materials, 217, 498-506, 2019. https://doi.org/10.1016/j.conbuildmat.2019.05.104.

[2] İ. Tekin, Properties of $\mathrm{NaOH}$ activated geopolymer with marble, travertine and volcanic tuff wastes. Construction and Building Materials, 127, 607-617, 2016.https://doi.org/10.1016/j.conbuildmat.2016.10.0 38.

[3] J. Davidovits, Geopolymers: Ceramic-like inorganic polymers, J. Ceram. Sci. Technol. 8, 335-350, 2017. https://doi.org/10.4416/JCST2017-00038.

[4] M. Kaya, M. Uysal, K. Yılmaz, O. Karahan, C. D. Atiş, Mechanical properties of class $\mathrm{C}$ and $\mathrm{F}$ fly ash geopolymer mortars. Gradevinar, 72 (4), 297-309, 2020. https://doi.org/10.14256/JCE.2421.2018.

[5] Ü. Yurt, High performance cementless composites from alkali activated GGBFS. Construction and Building Materials, 264, 120222, 2020. https://doi.org/10.1016/j.conbuildmat.2020.120222.

[6] M. Rostami and K. Behfarnia, The effect of silica fume on durability of alkali activated slag concrete. Construction and building materials, 134, 262-268, 2017.https://doi.org/10.1016/j.conbuildmat.2016.12.0 72.

[7] S. Çelikten, Mechanical and microstructural properties of waste andesite dust-based geopolymer mortars. Advanced Powder Technology, InPress, 2020. https://doi.org/ 10.1016/j.apt.2020.10.011.

[8] B. Coppola, P. Palmero, L. Montanaro, and J. M. Tulliani, Alkali-activation of marble sludge: Influence of curing conditions and waste glass addition. Journal of the European Ceramic Society, 40 (11), 3776-3787, 2020. https://doi.org/10.1016/j.jeurceramsoc.2019. 11.068 .

[9] U. Durak, O. Karahan, B. Uzal, S. İlkentapar, and C. D. Atiş, Influence of nano $\mathrm{SiO}_{2}$ and nano $\mathrm{CaCO}_{3}$ particles on strength, workability, and microstructural properties of fly ash-based geopolymer. Structural Concrete, 2020. https://doi.org/10.1002/suco.201900479.

[10] C. Bilim and C. D. Atiş, Alkali activation of mortars containing different replacement levels of ground granulated blast furnace slag. Construction and Building Materials, 28(1), 708-712, 2012. https://doi. org/10.1016/j.conbuildmat.2011.10.018.

[11] İ. İ. Atabey, O. Karahan, C. Bilim, C.D. Atiş, The influence of activator type and quantity on the transport properties of class F fly ash geopolymer. Construction and Building Materials, 264, 120268, 2020. https://doi.org/10.1016/j.conbuildmat.2020.120268.

[12] S. Çelikten, M. Sarıdemir, and İ.Ö. Deneme, Mechanical and microstructural properties of alkaliactivated slag and slag+ fly ash mortars exposed to high temperature. Construction and Building Materials, 217, 
50-61, 2019. https://doi.org/10.1016/j.conbuildmat. 2019.05.055.

[13] C. Villa, E. T. Pecina, R. Torres, and L. Gómez, Geopolymer synthesis using alkaline activation of natural zeolite. Construction and Building Materials, 24 (11), 2084-2090, 2010. https://doi.org/10.1016/ j.conbuildmat.2010.04.052.

[14] Ü. Yurt, B. Dündar, and E. Çınar, Jeopolimer betonlarda sülfürik asit etkisinin araştırılması. Düzce Üniversitesi Bilim ve Teknoloji Dergisi, 8 (2), 1548 1561,2020. https://doi.org/10.29130/dubited.644176.

[15] M. Sarıdemir, Alkali ile aktive edilmiş ögütülmüş diatomitli harçların dayanım özellikleri. Niğde Ömer Halisdemir Üniversitesi Mühendislik Bilimleri Dergisi, 5(2), 124-134, 2016. https://doi.org/10.28948/ ngumuh.294970.

[16] Ü. Yurt, An experimental study on fracture energy of alkali activated slag composites incorporated different fibers. Journal of Building Engineering, 101519, 2020. https://doi.org/10.1016/j.jobe.2020.101519.

[17] İ. İ Atabey, O. Karahan, C. Bilim, and C. Atiş, Very high strength $\mathrm{Na}_{2} \mathrm{SiO}_{3}$ and $\mathrm{NaOH}$ activated fly ash based geopolymer mortar. Cement Wapno Beton, 25, 292-305, 2020. https://doi.org/10.32047/cwb.2020.25. 4.4.

[18] V. Akyüncü, and M. T. Cihan, Bazalt tozu katkılı harçların mekanik ve geçirimlilik özeliklerinin araştırılması. Balıkesir Üniversitesi Fen Bilimleri Enstitüsü Dergisi, 21 (2), 697-707, 2019. https://doi.org/10.25092/ baunfbed.636998.

[19] H. Dilbas, and Ö. Çakır, Influence of basalt fiber on physical and mechanical properties of treated recycled aggregate concrete. Construction and Building Materials, 254, 119216, 2020. https://doi.org/10.1016/ j.conbuildmat.2020.119216.

[20] P. P. Li, Q. L. Yu, and H. J. H. Brouwers, Effect of coarse basalt aggregates on the properties of Ultra-high Performance Concrete (UHPC). Construction and Building Materials, 170, 649-659, 2018. https://doi.org/ 10.1016/j.conbuildmat.2018.03.109.

[21] M. Dobiszewska, and A. Beycioğlu, Investigating the influence of waste basalt powder on selected properties of cement paste and mortar. Materials Science and Engineering, 245 (2), 2017. https://doi.org/10.1088/ 1757-899X/245/2/022027.

[22] Çelikten S, Aktivatör türünün atık bazalt tozu esaslı jeopolimer harçların dayanım özelliklerine etkisi. Uluslararası Marmara Fen ve Sosyal Bilimler Kongresi IMASCON, Online/Kocaeli/Türkiye. 4-5 Kasım 2020.

[23] TS EN 1015-3, Kagir harc1- Deney metotlar1- Bölüm 3: Taze harç kıvamının tayini (yayılma tablası ile). Türk Standartları Enstitüsü, Ankara, 2006.
[24] TS EN 196 -1, Çimento Deney Metotları - Bölüm 1: Dayanım Tayini. Türk Standartları Enstitüsü, Ankara, 2016.

[25] S. Thokchom, P. Ghosh, and S. Ghosh, Effect of water absorption, porosity and sorptivity on durability of geopolymer mortars. ARPN Journal of engineering and Applied Sciences, 4(7), 28-32, 2009.

[26] J. N. Y. Djobo, A. Elimbi, H. K. Tchakouté, and S Kumar, Mechanical properties and durability of volcanic ash based geopolymer mortars. Construction and Building Materials, 124, 606-614, 2016. https://doi.org/10.1016/ j.conbuildmat.2016.07.141.

[27] Z. Zuhua, Y. Xiao, Z. Huajun, and C. Yue, Role of water in the synthesis of calcined kaolin-based geopolymer, Applied. Clay Science, 43 (2) 218-23 2009. https://doi.org/10.1016/j.clay.2008.09.003.

[28] M. Lizcano, A. Gonzalez, S. Basu, K. Lozano, and M. Radovic, Effects of water content and chemical composition on structural properties of alkaline activated metakaolin-based geopolymers. Journal of the American Ceramic Society, 95(7), 2169-2177, 2012 https://doi.org/10.1111/j.1551-2916.2012.05184.x.

[29] R. Pouhet, M. Cyr, R. Bucher, Influence of the initial water content in flash calcined metakaolin-based geopolymer Construction and Building Materials, 201, 421-429, 2019. https://doi.org/10.1016/j.conbuildmat. 2018.12.201.

[30] A. A. Aliabdo, M. Abd Elmoaty, and H. A. Salem, Effect of water addition, plasticizer and alkaline solution constitution on fly ash based geopolymer concrete performance. Construction and Building Materials, 121, 694-703, 2016. https://doi.org/10.1016/ j.conbuildmat.2016.06.062.

[31] P. R. Vora, and U. V. Dave, Parametric studies on compressive strength of geopolymer concrete. Procedia Engineering, 51, 210-219, 2013. https://doi.org/ 10.1016/j.proeng.2013.01.030.

[32] A. A. Aliabdo, M. Abd Elmoaty, and H. A. Salem, Effect of cement addition, solution resting time and curing characteristics on fly ash based geopolymer concrete performance. Construction and building materials, 123, 581-593 2016. https://doi.org/10.1016/ j.conbuildmat. 2016.07.043.

[33] B. H. Mo, H. Zhu, X. M. Cui, Y. He, S. Y. Gong, Effect of curing temperature on geopolymerization of metakaolin-based geopolymers. Applied clay science, 99, 144-148, 2014. https://doi.org/10.1016/j.clay.2014. 06.024 .

[34] S. Celikten, and B. Isikdag, Strength development of ground perlite-based geopolymer mortars. Advances in concrete construction, 9(3), 227-234, 2020. .https://doi.org/10.12989/acc.2020.9.3.227. 